\title{
The sub-ice platelet layer and its influence on freeboard to thickness conversion of Antarctic sea ice
}

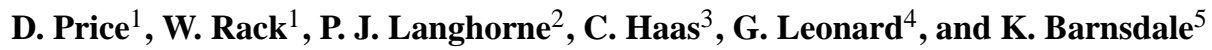 \\ ${ }^{1}$ Gateway Antarctica, University of Canterbury, Christchurch, New Zealand \\ ${ }^{2}$ Department of Physics, University of Otago, Dunedin, New Zealand \\ ${ }^{3}$ Department of Earth and Space Science and Engineering, York University, Canada \\ ${ }^{4}$ National School of Surveying, University of Otago, Dunedin, New Zealand \\ ${ }^{5}$ Spatial Engineering Research Centre, University of Canterbury, Christchurch, New Zealand \\ Correspondence to: D. Price (daniel.price@pg.canterbury.ac.nz)
}

Received: 17 January 2014 - Published in The Cryosphere Discuss.: 6 February 2014

Revised: 7 April 2014 - Accepted: 28 April 2014 - Published: 11 June 2014

\begin{abstract}
This is an investigation to quantify the influence of the sub-ice platelet layer on satellite measurements of total freeboard and their conversion to thickness of Antarctic sea ice. The sub-ice platelet layer forms as a result of the seaward advection of supercooled ice shelf water from beneath ice shelves. This ice shelf water provides an oceanic heat sink promoting the formation of platelet crystals which accumulate at the sea ice-ocean interface. The build-up of this porous layer increases sea ice freeboard, and if not accounted for, leads to overestimates of sea ice thickness from surface elevation measurements. In order to quantify this buoyant effect, the solid fraction of the sub-ice platelet layer must be estimated. An extensive in situ data set measured in 2011 in McMurdo Sound in the southwestern Ross Sea is used to achieve this. We use drill-hole measurements and the hydrostatic equilibrium assumption to estimate a mean value for the solid fraction of this sub-ice platelet layer of 0.16 . This is highly dependent upon the uncertainty in sea ice density. We test this value with independent Global Navigation Satellite System (GNSS) surface elevation data to estimate sea ice thickness. We find that sea ice thickness can be overestimated by up to $19 \%$, with a mean deviation of $12 \%$ as a result of the influence of the sub-ice platelet layer. It is concluded that within $100 \mathrm{~km}$ of an ice shelf this influence might need to be considered when undertaking sea ice thickness investigations using remote sensing surface elevation measurements.
\end{abstract}

\section{Introduction}

The increasing sea ice extent in the Ross Sea is the main contributor to the overall positive trend in the Antarctic sea ice cover as recorded over the satellite observational period (Parkinson and Cavalieri, 2012). The causes of this increase are unclear, but are likely linked to enhanced sea ice production in areas such as the Ross Sea Polynya and regional atmospheric cooling (Comiso et al., 2011). The southern Ross Sea is also characterised by the presence of ice shelf margins which are zones of abrupt physical change, in particular with regard to water mass interaction. At the large scale, the interaction of water sourced from ice shelf basal melting, which freshens the surface ocean, has been suggested as a potential contributor to increasing sea ice extent in the Southern Ocean (Bintanja et al., 2013). Of further interest, it is well known that the outflow of supercooled water from the ice shelf cavity creates an additional heat sink to the ocean promoting sea ice growth (Trodahl et al., 2000; Hellmer, 2004; Purdie et al., 2006; Gough et al., 2012), which increases sea ice thickness in close proximity to ice shelves (Hellmer, 2004; Purdie et al., 2006; Hughes et al., 2014). This additional ice that forms as a direct result of oceanic heat flux driven by the availability of supercooled water can be split into three components: platelet (or frazil) crystals suspended in the water column, an unconsolidated porous layer of sub-ice platelets directly beneath the sea ice and a layer of consolidated platelet ice incorporated into the sea ice (Dempsey et al., 2010). The subice platelet layer, which does not contribute to the mechanical integrity of the sea ice cover, and has a very different 
density than consolidated ice, creates an additional source of buoyancy, resulting in an increase in sea ice freeboard. Currently the use of sea ice freeboard measurements from satellite altimetry is the only method to derive large-scale sea ice thickness estimates in the Antarctic (Kurtz and Markus, 2012). Using a freeboard measurement alone to estimate sea ice thickness under the hydrostatic equilibrium assumption could result in an overestimation of sea ice thickness - if the influence of the unknown sub-ice platelet layer thickness turns out to be significant. Further, spatial anomalies in sea ice thickness may be interpreted as indictors of the presence of a sub-ice platelet layer, which in turn may infer the presence of supercooled ice shelf water (ISW) (Hughes et al., 2014). As it is very common for sea ice to abut ice shelves in the Antarctic (Bindschadler et al., 2011), and the extent and persistence of the sub-ice platelet layer is substantially unknown, we consider here the effects of this layer on estimates of sea ice thickness.

The estimation of remotely sensed sea ice thickness from freeboard information is based on altimetric methods. In the simplest sense the difference between altimetric measurements of the local sea surface height and the sea ice elevation provides the freeboard, which can be used in conjunction with snow depth and the densities of ice and snow to estimate sea ice thickness (Zwally et al., 2008; Kurtz and Markus, 2012; Price et al., 2013). The additional influence of the sub-ice platelet layer has not yet been considered. In order to assess this influence the solid fraction (sf) of the subice platelet layer must be derived. Here sf defines the solid volume of ice per total volume and hence can be calculated from the buoyancy contribution of this layer to the sea ice cover above. The direct measurement of sf is complicated by the inaccessible environment beneath sea ice and the immediate alteration of its properties upon disturbance by drilling due to the unconsolidated nature of the layer. Previous investigations have provided values from 0.2 to 0.5 for sf of the sub-ice platelet layer (Gough et al., 2012).

Here we firstly discuss deriving sf under the hydrostatic equilibrium assumption and the influential components which must be considered. We then describe our in situ data set from McMurdo Sound in the southwestern Ross Sea (Fig. 1) and briefly describe the sea ice conditions (Figs. 2 and 3). Using this information we estimate a sf value (Fig. 4). We then focus on total freeboard (ice-plus-snow) measurements using Global Navigation Satellite System (GNSS) data to estimate sea ice thickness and, given our estimate of the sf, demonstrate how these GNSS-based estimates are influenced by the presence of a sub-ice platelet layer. Given that GNSSbased estimates of sea ice thickness follow the same principles of surface elevation to thickness conversion as satellite altimeter measurements, we consider the observed effects to be applicable to both techniques. Equally, although we use a localised region to constrain our values, we expect the formation of the sub-ice platelet layer to be similar in comparable areas of coastal Antarctic sea ice that abut an ice shelf. There-
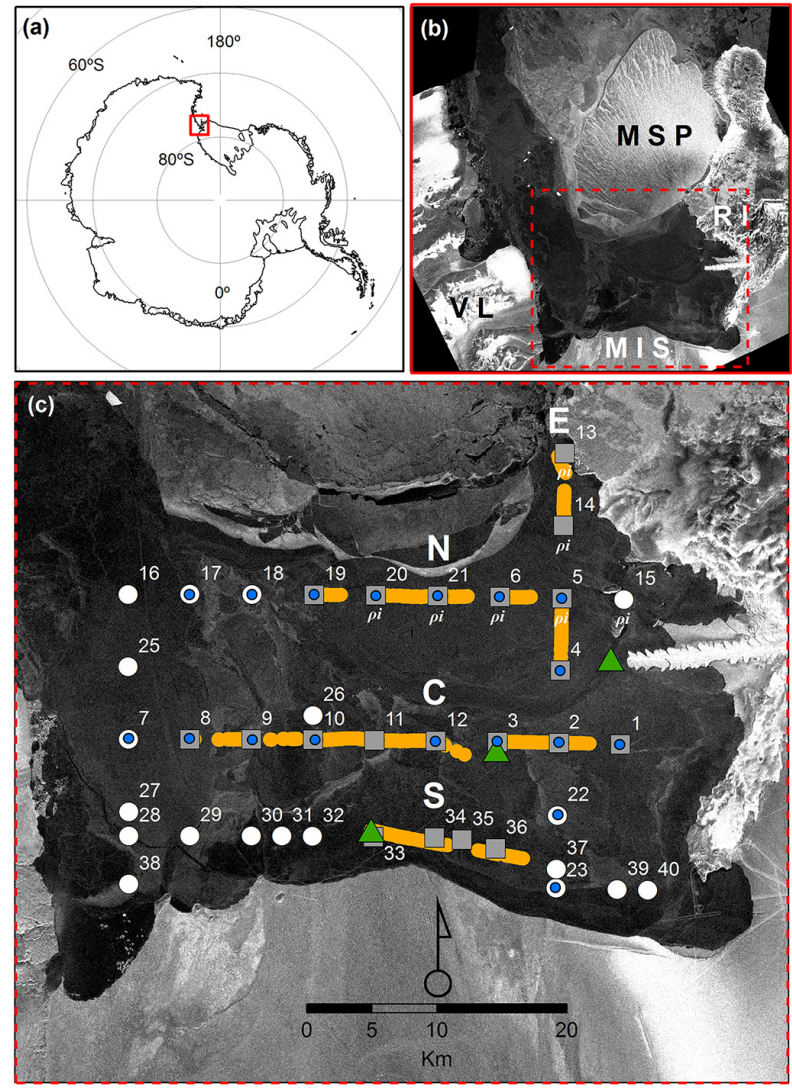

Figure 1. (a) Location of the study area. (b) Envisat Wide Swath Advanced Synthetic Aperture Radar (ASAR) image (31 August 2011) of McMurdo Sound showing the first-year fast ice area. The McMurdo Sound Polynya (MSP) is driven by offshore winds from Ross Island (RI) in the east. Victoria Land (VL) and the McMurdo Ice Shelf (MIS) are also identified. (c) Magnified view of red box in (b) with an ASAR image from 28 September 2011. Drill-hole measurement sites are indicated by white dots, those used for comparison with the GNSS surveys by grey squares. The GNSS survey lines, Northern, Central, Southern and Eastern are indicated by the orange lines and tidal GNSS stations for tide correction by the green triangles. The 18 sites at which snow density was measured are indicated with blue circles; the 7 sites at which sea ice density was estimated using the hydrostatic equilibrium assumption are shown with " $\rho_{\mathrm{i}}$ " underneath the measurement site.

fore, conclusions about its influence may be considered at the larger scale.

\section{Estimating solid fraction under the hydrostatic equilibrium assumption}

To calculate the buoyant influence of the sub-ice platelet layer upon the sea ice cover above, sf must first be derived. Assuming hydrostatic equilibrium sf may be calculated as

$\mathrm{sf}=\frac{-\left(\rho_{\mathrm{w}}-\rho_{\mathrm{i}}\right) T_{\mathrm{i}}+\left(\rho_{\mathrm{w}} \mathrm{SE}\right)-\left(\rho_{\mathrm{w}}-\rho_{\mathrm{s}}\right) T_{\mathrm{s}}}{\left(\rho_{\mathrm{w}}-\rho_{\mathrm{i}}\right) T_{\mathrm{p}}}$, 
(a)

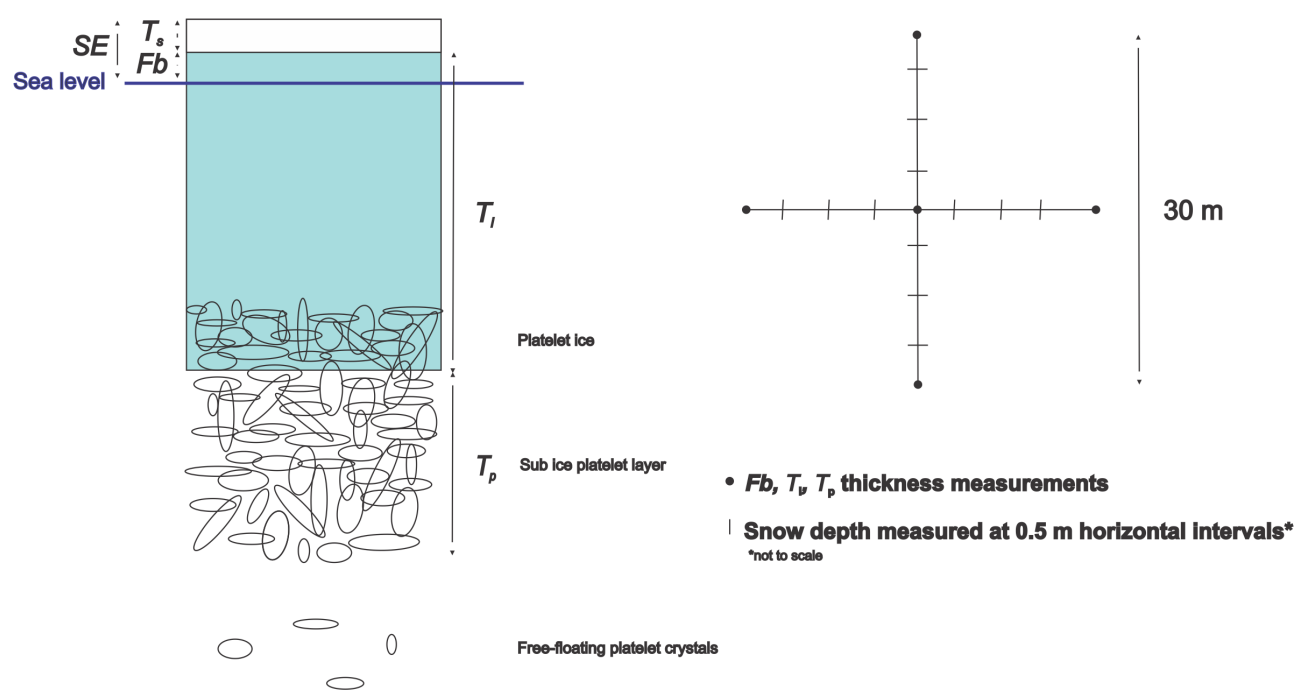

(b)

Figure 2. (a) Typical vertical profile through first-year sea ice in McMurdo Sound in austral spring, adapted from Gough et al. (2012) Surface elevation (SE) describes the combined protrusion of the ice freeboard $(\mathrm{Fb})$ and snow cover $\left(T_{\mathrm{S}}\right)$ above sea level. Ice thickness $\left(T_{\mathrm{i}}\right)$ describes the sea ice formed from heat flux to the atmosphere along with the platelet ice which is the incorporated as the sea ice-ocean interface advances into accumulating platelets below. The sub-ice platelet layer accumulates beneath $\left(T_{\mathrm{p}}\right)$. Platelet crystals float freely in the water column below. (b) Graphical display of the drill-hole measurement site setup.

where $\rho_{\mathrm{w}}, \rho_{\mathrm{i}}$ and $\rho_{\mathrm{s}}$ are the densities of water, sea ice and snow respectively and $T_{\mathrm{i}}, T_{\mathrm{p}}$ and $T_{\mathrm{s}}$ are sea ice thickness, sub ice platelet layer thickness and snow depth respectively (see illustration Fig. 2). Surface elevation (SE) is the elevation of the snow/air interface (or ice/air interface if $T_{\mathrm{s}}=0$ ) relative to sea level. For our study all values were measured simultaneously at drill holes (see Sect. 3) for the derivation of sf apart from $\rho_{\mathrm{w}}, \rho_{\mathrm{s}}$ and $\rho_{\mathrm{i}}$. We use a constant value of $1027 \mathrm{~kg} \mathrm{~m}^{-3}$ for $\rho_{\mathrm{w}}$ as there is little variability in observed sea water density $(0.1 \%)$ in this area (Albrecht et al., 2006). Uncertainty in $\rho_{\mathrm{w}}$ is therefore ignored. For $\rho_{\mathrm{s}}$ we use the values measured in the field at 18 sites in McMurdo Sound in November and December 2011 (Fig. 1) ranging between 281 and $461 \mathrm{~kg} \mathrm{~m}^{-3}$. At sites where no data are available we use the mean value of all the measurements of $385 \mathrm{~kg} \mathrm{~m}^{-3}$.

The selection of a value for $\rho_{\mathrm{i}}$ is complicated by the range in measurements from different techniques and the fact that sea ice density exhibits large natural variability. Timco and Frederking (1996) report mean $\rho_{\mathrm{i}}$ values for first-year (FY) sea ice in the range of 900 to $920 \mathrm{~kg} \mathrm{~m}^{-3}$. Previous unpublished direct measurements of $\rho_{\mathrm{i}}$ in McMurdo Sound from one co-author (Langhorne) have been obtained via the displacement method in 1992, 1994 and 1996. The 160 measurements of $\rho_{\mathrm{i}}$ ranged between 900 and $925 \mathrm{~kg} \mathrm{~m}^{-3}$, the mean of these previously unpublished data being $915 \mathrm{~kg} \mathrm{~m}^{-3}$. The $\rho_{\mathrm{i}}$ can also be estimated using the hydrostatic equilibrium assumption. However, this must be carried out in areas where no sub-ice platelet layer is present.
Using this method in McMurdo Sound, Gough et al. (2012) report $\rho_{\mathrm{i}}$ as $934 \mathrm{~kg} \mathrm{~m}^{-3}$. Using an amended method at seven of our measurement sites in 2011 (where $\rho_{\mathrm{i}}$ estimate for each site is the mean of $\rho_{\mathrm{i}}$ derived from five drill-hole measurements - see Fig. 2b) where no sub-ice platelet layer was measured we obtain a mean value of $927 \mathrm{~kg} \mathrm{~m}^{-3}$. The locations of these sites are indicated in Fig. 1. Given this information, and considering the uncertainties, we use a value of $\rho_{\mathrm{i}}=925 \mathrm{~kg} \mathrm{~m}^{-3}$ in our calculations which represents the middle range of expected $\rho_{\mathrm{i}}$ in McMurdo Sound. We evaluate and discuss the density-dependent sensitivity of sf in the following sections.

The total error for sf can be estimated by error propagation from Eq. (1) using (Drosg, 2009)

$$
\sigma_{\mathrm{sf}}=\left[\begin{array}{l}
\left(\frac{\rho_{\mathrm{w}} \mathrm{SE}+\rho_{\mathrm{s}} T_{\mathrm{s}}-\rho_{\mathrm{w}} T_{\mathrm{s}}}{T_{\mathrm{p}}\left(\rho_{\mathrm{w}}-\rho_{\mathrm{i}}\right)^{2}} \sigma_{\rho_{\mathrm{i}}}\right)^{2}+\left(-\frac{1}{T_{\mathrm{p}}} \sigma_{T_{\mathrm{i}}}\right)^{2} \\
+\left(\frac{\rho_{\mathrm{w}}}{\left(\rho_{\mathrm{w}}-\rho_{\mathrm{i}}\right) T_{\mathrm{p}}} \sigma_{\mathrm{SE}}\right)^{2}+\left(\frac{T_{\mathrm{s}}}{\left(\rho_{\mathrm{w}}-\rho_{\mathrm{i}}\right) T_{\mathrm{p}}} \sigma_{\rho_{\mathrm{s}}}\right)^{2} \\
+\left(\frac{\rho_{\mathrm{s}}-\rho_{\mathrm{w}}}{\left(\rho_{\mathrm{w}}-\rho_{\mathrm{i}}\right) T_{\mathrm{p}}} \sigma_{T_{\mathrm{s}}}\right)^{2} \\
+\left(-\frac{1}{T_{\mathrm{p}}^{2}}\left(\frac{\rho_{\mathrm{w}} \mathrm{SE}+\rho_{\mathrm{s}} T_{\mathrm{s}}-\rho_{\mathrm{w}} T_{\mathrm{s}}}{\left(\rho_{\mathrm{w}}-\rho_{\mathrm{i}}\right)}-T_{\mathrm{i}}\right) \sigma_{T_{\mathrm{p}}}\right)^{2}
\end{array}\right]^{1 / 2},
$$

where we expect random and independent measurement errors for $\sigma_{\rho_{\mathrm{i}}}, \sigma_{T_{\mathrm{i}}}, \sigma_{\mathrm{SE}}, \sigma_{\rho_{\mathrm{S}}}, \sigma_{T_{\mathrm{S}}}$ and $\sigma_{T_{\mathrm{p}}}$ to be $10 \mathrm{~kg} \mathrm{~m}^{-3}$, $0.02 \mathrm{~m}, 0.01 \mathrm{~m}, 50 \mathrm{~kg} \mathrm{~m}^{-3}, 0.05$ and $0.10 \mathrm{~m}$ respectively. All thickness measurement uncertainties are estimated from experience with field measurements. The $\rho_{\mathrm{i}}$ uncertainty is given 
by the spread of values recorded for $\rho_{\mathrm{i}}$ in McMurdo Sound between 915 and $934 \mathrm{~kg} \mathrm{~m}^{-3}$. The $\rho_{\mathrm{s}}$ uncertainty is indicated by the standard deviation of measurements carried out in 2011.

As we derive sf and $\sigma_{\mathrm{sf}}$ from SE, $T_{\mathrm{i}}, T_{\mathrm{p}}, T_{\mathrm{S}}$ and $\rho_{\mathrm{s}}$, the collection of these measurements from a dedicated in situ fieldwork campaign in McMurdo Sound in November and December 2011 is described in the next section.

\section{In situ investigation}

An extensive drill-hole measurement campaign was carried out in November and December 2011 collecting information on freeboard, snow depth and snow density, sea ice thickness and sub-ice platelet layer thickness for FY sea ice in McMurdo Sound (Fig. 1).

\subsection{Drill-hole measurements}

Measurements were undertaken at 39 sites distributed across an area of approximately $1000 \mathrm{~km}^{2}$ in the southern Sound. Cross-profiles with $30 \mathrm{~m}$ transects were established at each site, and snow depths were measured at $0.5 \mathrm{~m}$ intervals with a ruler (Fig. 2). A mean snow depth for each site was derived from these 120 measurements. Freeboard, ice thickness and sub-ice platelet layer thickness were recorded at five locations at each site, once at the central crossing point and at the end points of each transect (Fig. 2). The mean of these was then calculated and taken as representative of the site. Ice thicknesses were measured by using a tape measure with a brass T-anchor attached at the zero mark (Haas and Druckenmiller, 2009). This was deployed vertically through the drillhole and allowed to rotate to a horizontal alignment when exiting the bottom of the drill-hole at the ice-ocean interface. From this position, and as described in Gough et al. (2012) the anchor is slowly pulled upward until some resistance is met and the first measurement is taken. This resistance is taken to mark the sub-ice platelet layer/ocean interface. The tape measure is then pulled harder, forcing the bar to pass through the sub-ice platelet layer until it sits flush against the sea ice/sub-ice platelet layer interface where a second measurement is taken. Snow density was measured at half of the drill-hole sites using a density tube and spring balance. Freeboard, ice thickness and sub-ice platelet layer thickness and snow depth were interpolated between sites to produce thickness maps (Fig. 3) using a natural neighbour interpolation method with a maximum point separation of approximately $11 \mathrm{~km}$.

\subsection{Maps of sea ice and snow cover characteristics}

Prior to our measurements in November and December 2011 the fast FY sea ice in McMurdo Sound experienced undisturbed growth for a minimum of 5 months. There is a clear ice thickness gradient from east to west (Fig. 3). Thinner ice with a typical thickness of $1.5 \mathrm{~m}$ is commonplace in the east, particularly in the northeast, becoming gradually thicker to the west, where it reaches $2.5 \mathrm{~m}$ in thickness. This is significantly higher than the pack ice of the Ross Sea which typically has a thickness of $1 \mathrm{~m}$ or less (Worby et al., 2008; Kurtz and Markus, 2012). In comparison to other fast ice areas, McMurdo Sound sea ice thickness is still greater than expected. Uto et al. (2006) report that land-fast FY ice in eastern Antarctica which had been growing for 4-5 months was typically up to $1.5 \mathrm{~m}$ in thickness. This is comparable to thicknesses in the northeast of McMurdo Sound. The mean sea ice thickness as derived from all 39 drill-hole measurement sites was $2.11 \mathrm{~m}$. In the southwest, sea ice had been growing for approximately 7 months, two months longer than in the northeast. This is the first of three mechanisms likely responsible for the observed sea ice thickness distribution. The ISW plume is the second mechanism. The influence of this plume on sea ice processes has been documented in studies of sea ice structure and growth (Langhorne et al., 2006; Dempsey et al., 2010; Mahoney et al., 2011; Gough et al., 2012). Satellite altimeter observations have indicated that the locations of the largest increases in multiyear sea ice thickness from 2003-2009 during the NASA ICESat mission (Price et al., 2013) were coincident with the greatest abundance of platelet ice (Dempsey et al., 2010). This region has recently been identified as the location of an ISW plume (Robinson et al., 2014). The thickness and density distributions revealed by a localised airborne freeboard and thickness investigation of the MIS margin in 2009 (Rack et al., 2013) are supportive of the emergence of such a plume into McMurdo Sound. In 2011, sea ice in the west was comprised almost entirely of platelet ice (Hughes et al., 2014) as would also be expected from the presence of such a plume. The subice platelet layer has an east-west distribution commensurate with the presence of this plume (Hughes et al., 2014). The layer is thickest where it protrudes from the MIS front between 165 and $165^{\circ} 30^{\prime} \mathrm{E}$, where it has been measured as $7.5 \mathrm{~m}$ in thickness (Figs. 3 and 5). As expected, the sub-ice platelet layer distribution closely follows the platelet distribution, as described by Dempsey et al. (2010). As it is not a solid structure and may be mobile, the sub-ice platelet layer thickness at a single location may be highly variable over short timescales of hours to days.

The third mechanism which plays a role in the observed sea ice thickness distribution is snow cover. Limited published information is available on the snow depth distribution in McMurdo Sound. Gow et al. (1998) reported very generally that snow thickness was greatest in close proximity to the MIS front decreasing to only trace amounts in remote areas 

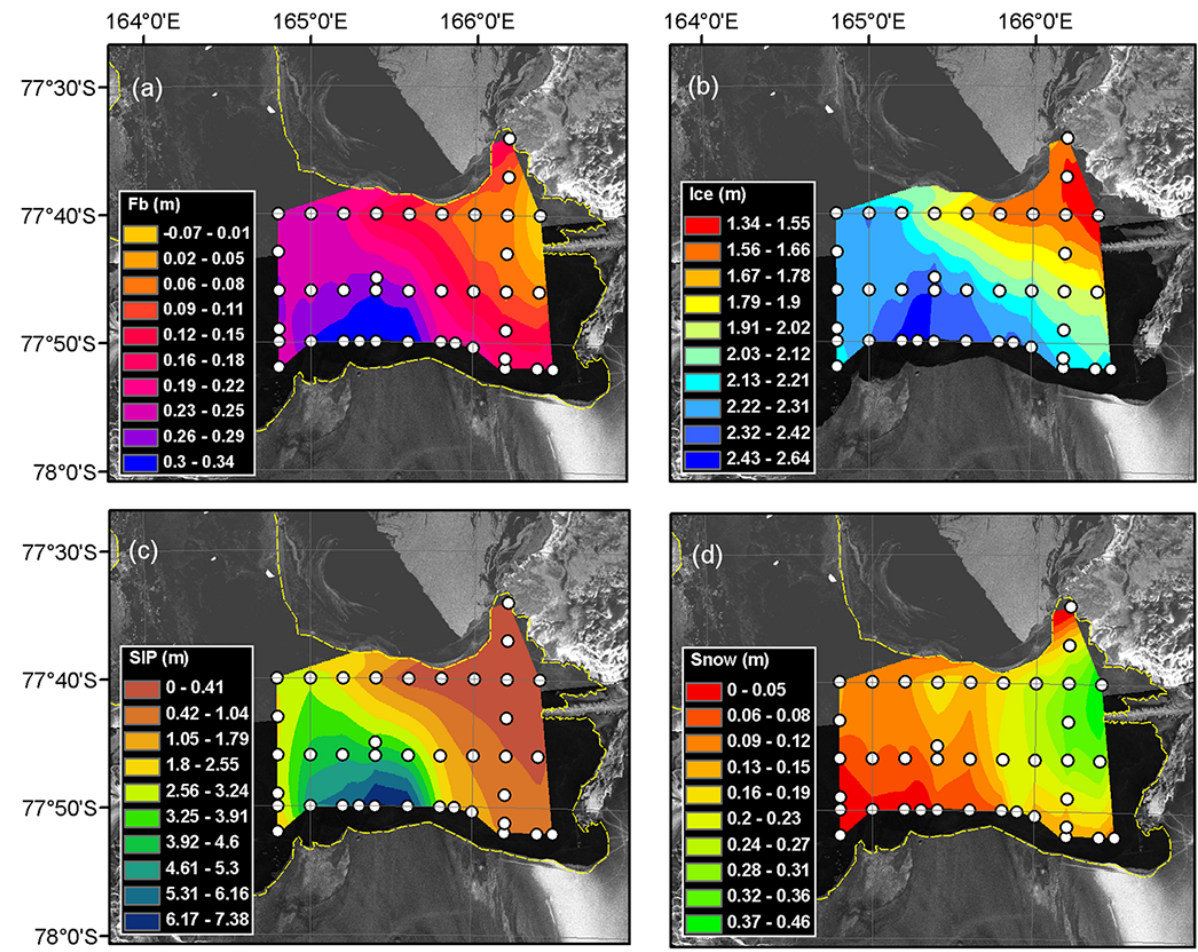

Figure 3. Interpolated maps of drill-hole measurements of (a) freeboard (b) ice thickness, (c) sub-ice platelet layer thickness (SIP) and (d) snow thickness of first-year sea ice in McMurdo Sound in November and December 2011. These are overlaid upon an Envisat ASAR mosaic composed of two images from 25 and 28 November.

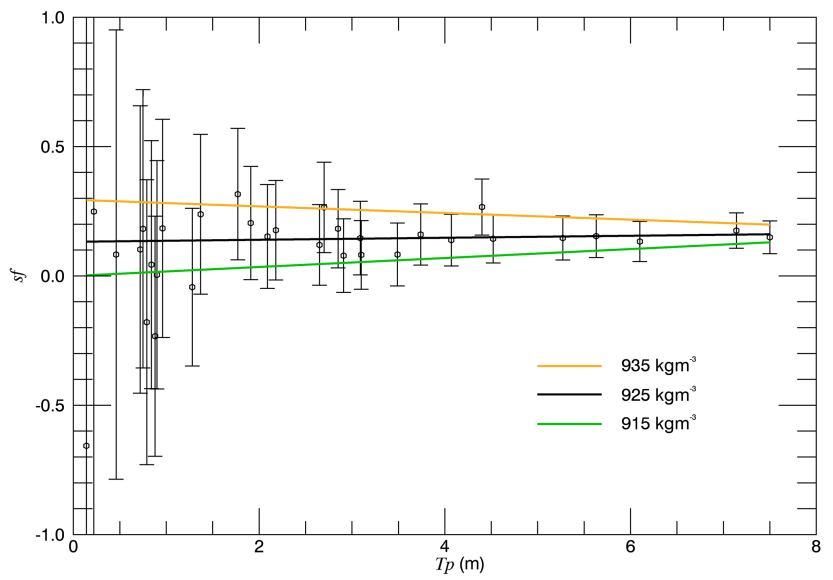

Figure 4. Solid fraction (sf) derived by Eq. (1) (black circles) and expected errors from Eq. (2) derived for 32 measurement sites. A linear fit is shown in black for this data set. The influence of varying sea ice density $\left(\rho_{\mathrm{i}}\right)$ is also displayed as linear fits for higher and lower $\rho_{\mathrm{i}}$ values (no symbols plotted). of McMurdo Sound. In 2011, the snow cover in the west and the central parts was patchy, with small-scale dune features with thicknesses in the order of decimetres and with exposed sea ice in many places. There is a clear east-west gradient in this pattern, contrary to the sea ice thickness pattern, with deeper snow in the east gradually becoming thinner to the west. In the east, where the snow is thicker, it acts as an insulating layer from the atmosphere, limiting sea ice growth. In the west where it is thinner or absent, greater heat flux to the atmosphere results, which in turn facilitates the formation of thicker sea ice.

\section{The solid fraction in McMurdo Sound}

Using our drill-hole measurements, the derived sf values using Eq. (1) and the expected error $\left(\sigma_{\mathrm{sf}}\right)$ from Eq. (2) are shown in black in Fig. 4 with $\rho_{\mathrm{i}}=925 \mathrm{~kg} \mathrm{~m}^{-3}$. The derivation of sf is especially sensitive if the sub-ice platelet layer is less than $2 \mathrm{~m}$ thick. Sites at which the sub-ice platelet layer is thin commonly produce negative sf values especially when $\rho_{\mathrm{i}}<920 \mathrm{~kg} \mathrm{~m}^{-3}$. Using 32 of 39 sites in our investigation where a sub-ice platelet layer is present and with the removal of 9 further sites where the sub-ice platelet layer was less than $1.5 \mathrm{~m}$ results in a mean sf value of $0.16 \pm 0.07$. Figure 4 displays all sites where a sub-ice platelet layer was present and also linear fits of sf with $\rho_{\mathrm{i}}=915 \mathrm{~kg} \mathrm{~m}^{-3}$ (green line) 
and $\rho_{\mathrm{i}}=935 \mathrm{~kg} \mathrm{~m}^{-3}$ (orange line). This clearly demonstrates firstly the dependence of sf estimates on $\rho_{\mathrm{i}}$ and secondly the high sensitivity of the sf calculation where the sub-ice platelet layer is thin.

\section{Sea ice thickness from GNSS-derived surface elevation}

GNSS elevation data were collected for positional and height information across the Sound. The GNSS-derived ellipsoidal heights, relative to WGS-84, were calibrated to produce total freeboard (ice-plus-snow) measurements, herein described as GNSS surface elevation ( $\mathrm{SE}_{\mathrm{GNSS}}$ ). This calibration was achieved by applying a correction value derived from comparison of drill-hole measured surface elevation (SE) and all GNSS height measurements within $0.5 \mathrm{~km}$ of the drillhole measurement. This altered the reference frame of the GNSS height data from the WGS-84 ellipsoid to elevation above local sea level and permitted surface elevation information to be recorded at increased spatial resolution along each of the four profiles: northern, central, southern and eastern. Initially sampled at $1 \mathrm{~Hz}$, the GNSS observations were averaged along-track resulting in a ground separation of approximately $100 \mathrm{~m}$. GNSS positions were established using the Precise Relative GNSS technique, referenced to the Scott Base base station located on Ross Island's Hutt Point Peninsula at $77.85^{\circ} \mathrm{S}, 166.76^{\circ} \mathrm{E}$. After processing with Trimble Business Centre, mean horizontal and vertical precision were shown to be 0.04 and $0.09 \mathrm{~m}$ respectively. All data where the expected vertical precision was greater than $0.17 \mathrm{~m}$ were removed. This value was chosen as it removed erroneous data in the west where GNSS precision was lower due to the larger baseline distance (anything over approximately $40 \mathrm{~km}$ ). In order to compensate for the tidal influence on the GNSS height and subsequently the $\mathrm{SE}_{\mathrm{GNSS}}$ retrieval, three separate GNSS stations were deployed on the fast ice (see Fig. 1 for locations). These tidal stations logged height information at $30 \mathrm{~s}$ intervals, which was subsequently down-sampled to 10 min intervals. As the transit time of the mobile GNSS on the sea ice was hours, this information was used to correct the rover GNSS information for tidal height variation between drill-hole cross-over points. There was no discernible gradient in the tidal signal between the three tidal GNSS stations. Changes in elevation due to tides were taken from the closest tidal GNSS station to the mobile observation to correct $\mathrm{SE}_{\mathrm{GNSS}}$ at the time of acquisition.

In order to derive sea ice thickness from $\mathrm{SE}_{\mathrm{GNSS}}$ we need to take into account the effect of the sub-ice platelet layer. Following Zwally et al. (2008) we estimate sea ice thickness without taking account of the sub-ice platelet layer $\left(T_{\mathrm{ip}}\right)$ in Eq. (3) and then taking account of it $\left(T_{\mathrm{i}}\right)$ in Eq. (4):

$$
T_{\mathrm{ip}}=\frac{\rho_{\mathrm{w}}}{\rho_{\mathrm{w}}-\rho_{\mathrm{i}}} \mathrm{SE} E_{\mathrm{GNSS}}-\frac{\rho_{\mathrm{w}}-\rho_{\mathrm{s}}}{\rho_{\mathrm{w}}-\rho_{\mathrm{i}}} T_{\mathrm{S}}
$$

Table 1. The mean of all drill-hole measurements used along the profiles $(n=20)$ of $2.00 \pm 0.31$ corresponds better to a surface elevation derived sea ice thickness accounting for the sub-ice platelet layer $\left(T_{\mathrm{i}}\right)$ of $2.11 \pm 0.85 \mathrm{~m}$, than one in which it is ignored $\left(T_{\mathrm{ip}}\right)$ giving $2.39 \pm 0.99 \mathrm{~m}$.

\begin{tabular}{lllll}
\hline Profile & Drill-hole $(\mathrm{m})$ & $T_{\mathrm{ip}}(\mathrm{m})$ & $T_{\mathrm{i}}(\mathrm{m})$ & Mean $T_{\mathrm{p}}(\mathrm{m})$ \\
\hline Northern & $1.69 \pm 0.13$ & $1.96 \pm 0.77$ & $1.93 \pm 0.75$ & $0.24 \pm 0.42$ \\
Central & $2.19 \pm 0.16$ & $2.62 \pm 1.02$ & $2.21 \pm 0.90$ & $2.53 \pm 1.70$ \\
Southern & $2.33 \pm 0.06$ & $2.88 \pm 0.70$ & $2.32 \pm 0.56$ & $3.30 \pm 2.29$ \\
Eastern & $1.60 \pm 0.10$ & $1.92 \pm 1.02$ & $1.92 \pm 1.02$ & $0.04 \pm 0.06$ \\
\hline
\end{tabular}

$T_{\mathrm{i}}=\frac{\rho_{\mathrm{w}}}{\rho_{\mathrm{w}}-\rho_{\mathrm{i}}} \mathrm{SE}_{\mathrm{GNSS}}-\frac{\rho_{\mathrm{w}}-\rho_{\mathrm{s}}}{\rho_{\mathrm{w}}-\rho_{\mathrm{i}}} T_{\mathrm{s}}-T_{\mathrm{p}} \mathrm{sf}$.

All density values described in Sect. 2 are used here with $\mathrm{sf}=0.16$ as described in Sect. 4. Taking account of all the information described above, we calculated the sea ice thickness along four continuous GNSS surface elevation profiles using Eqs. (3) and (4) (Fig. 5), the mean estimates of which are shown in Table 1. These are compared to coincident measured drill-hole thickness. Taking the mean for all of the profiles the deviation from drill-hole measured sea ice thickness improves by $0.28 \mathrm{~m}$ when the sub-ice platelet layer is taken into consideration. The northern, central and southern profiles show a shift towards drill-hole sea ice thickness. The southern profile shows a drastic improvement from a mean deviation of $+0.55 \mathrm{~m}$ in thickness neglecting the subice platelet layer to $-0.01 \mathrm{~m}$ when accounting for it. The central profile improves from a mean deviation of $+0.43 \mathrm{~m}$ from the drill-hole measurements when estimating $T_{\text {ip }}$ to $+0.02 \mathrm{~m}$ when estimating $T_{\mathrm{i}}$. The northern profile improves by $0.03 \mathrm{~m}$ but still deviates from the drill-hole sea ice thickness mean by $+0.24 \mathrm{~m}$. This small change from $T_{\mathrm{ip}}$ to $T_{\mathrm{i}}$ is resultant of a negligible mean sub-ice platelet layer thickness of 0.24 $\mathrm{m}$. The eastern profile shows no change as the platelet layer recorded there was very thin with a mean thickness of $0.04 \mathrm{~m}$. The northern and eastern profiles both have a bias toward higher sea ice thickness estimates than measured at the drillholes. This could be a result of the interpolations' inability to capture the small-scale variability of the snow cover. This could result in underestimations of snow depth and subsequently high sea ice thickness estimates.

As the sub-ice platelet layer is not the only source of error when estimating sea ice thickness, a full error assessment is shown below. Following Spreen et al. (2006, Eq. (2)) with the additional inclusion of the sub-ice platelet layer uncertainty we estimate our final error in sea ice thickness once accounting for the sub-ice platelet layer $\left(\sigma_{T_{\mathrm{i}}}\right)$ as 

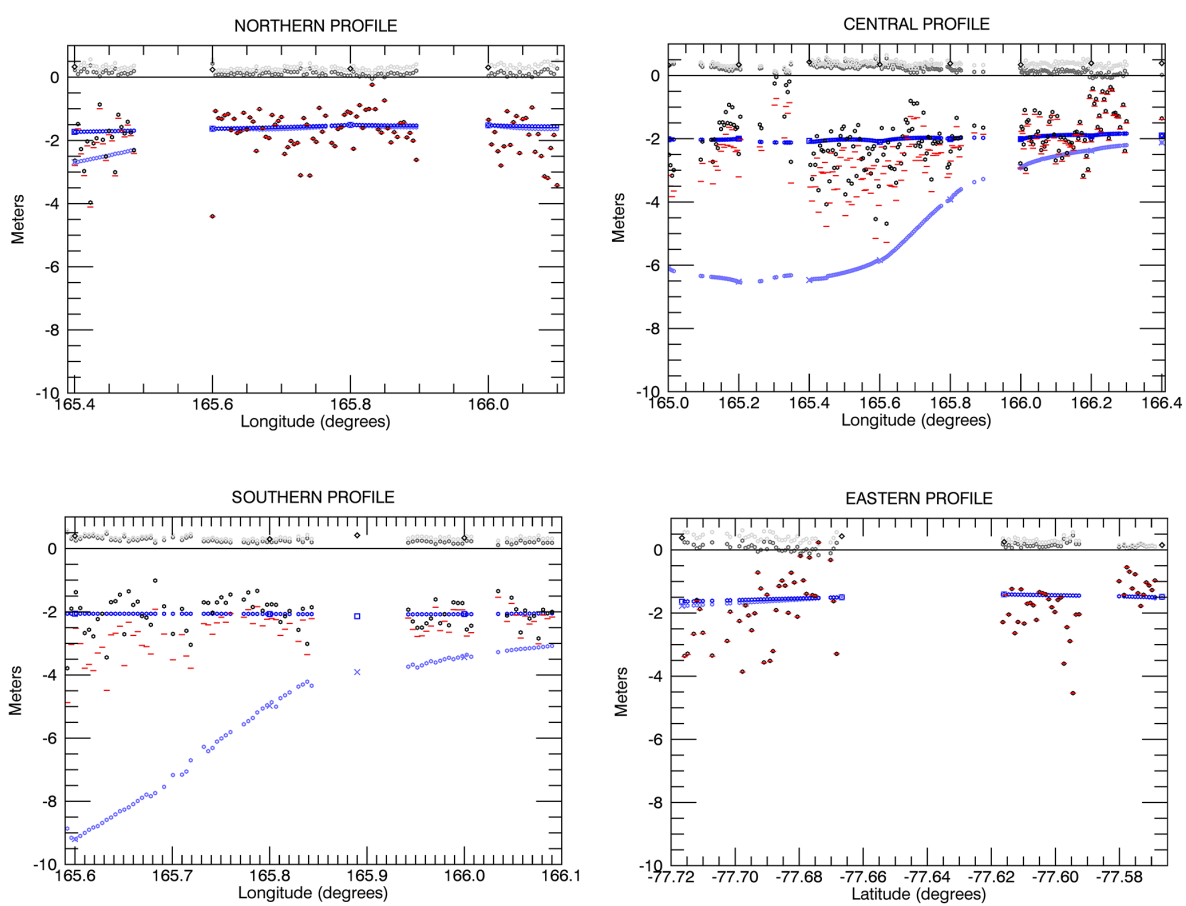

Figure 5. The four profiles with GNSS-derived surface elevation (light grey), interpolated drill-hole derived sea ice freeboard (dark grey), sea ice draft (dark blue) and sub-ice platelet layer draft (light blue). Red dashes indicate sea ice draft as predicted by Eq. (3) taking no account of the sub-ice platelet layer, black circles indicate the estimated draft with consideration of the sub-ice platelet layer as estimated by Eq. (4). Drill-hole measurements of surface elevation $(\diamond)$, sea ice draft $(\square)$ and sub-ice platelet layer draft $(\times)$ are also displayed for comparison with the interpolations.

$\sigma_{T_{\mathrm{i}}}=\left[\begin{array}{l}\left(\frac{\rho_{\mathrm{w}}}{\rho_{\mathrm{w}}-\rho_{\mathrm{i}}} \sigma_{\mathrm{SE}_{\mathrm{GNSS}}}\right)^{2}+\left(\frac{\rho_{\mathrm{s}}-\rho_{\mathrm{w}}}{\rho_{\mathrm{w}}-\rho_{\mathrm{i}}} \sigma_{T_{\mathrm{s}}}\right)^{2} \\ +\left(\frac{T_{\mathrm{s}}\left(\rho_{\mathrm{s}}-\rho_{\mathrm{w}}\right)+\mathrm{SE}_{\mathrm{GNSS}} \rho_{\mathrm{w}}}{\left(\rho_{\mathrm{w}}-\rho_{\mathrm{i}}\right)^{2}} \sigma_{\rho_{\mathrm{i}}}\right)^{2} \\ +\left(\frac{T_{\mathrm{s}}}{\rho_{\mathrm{w}}-\rho_{\mathrm{i}}} \sigma_{\rho_{\mathrm{s}}}\right)^{2} \\ +\left(\sigma_{T_{\mathrm{p}}} \mathrm{s}\right)^{2}+\left(\sigma_{\mathrm{sf}} T_{\mathrm{p}}\right)^{2}\end{array}\right]^{1 / 2}$.

Here we estimate uncertainties in $\rho_{\mathrm{i}}$ and $\rho_{\mathrm{s}}$ to be 10 and $60 \mathrm{~kg} \mathrm{~m}^{-3}$ respectively as indicated by the standard deviations of field measurements. $T_{\mathrm{S}}$ and $T_{\mathrm{p}}$ values used in the thickness calculation are from the interpolation of the measurement sites. Leave-one-out cross-validation was used with random selection to assess the accuracy of our interpolation method. Eight drill-hole sites were removed in turn and eight separate interpolations run. This procedure indicated a mean absolute deviation between the removed snow thickness measurement and subsequent interpolation of $0.05 \mathrm{~m}$ for $T_{\mathrm{s}}$ and $0.23 \mathrm{~m}$ for $T_{\mathrm{p}}$. These values are used for the uncertainties in each thickness. The uncertainty in sf is $45 \%$. The main contributor to the error in sea ice thickness estimation from GNSS measurements is the accuracy of the GNSS surface elevation measurement itself. The mean GNSS vertical elevation uncertainty as indicated by the processing software is $0.09 \mathrm{~m}$. At least 20 measurements are included in our along-track averaging to $100 \mathrm{~m}$ spacing reducing the random error in surface elevation measurements to $0.02 \mathrm{~m}$, i.e. $\sigma \mathrm{SE}_{\mathrm{GNSS}}=\frac{0.09}{\sqrt{20}}$. For a single GNSS measurement this results in an expected sea ice thickness error of $0.58 \mathrm{~m}$ once the sub-ice platelet layer has been taken into account.

\section{Discussion}

Using our drill-hole measurements we have indirectly estimated a mean solid fraction (sf) of the sub-ice platelet layer for McMurdo Sound of $0.16 \pm 0.07$. This is lower than previous estimates, but still within the uncertainty from Gough et al. (2012) of $0.25 \pm 0.06$, who base their estimate on the measurement of heat fluxes. Our estimate is based on mean freeboard and thickness measurements by applying the hydrostatic equilibrium assumption. The primary systematic uncertainty in the sf estimation is sea ice density $\left(\rho_{\mathrm{i}}\right)$. Our result uses a mean $\rho_{\mathrm{i}}$ value of $925 \mathrm{~kg} \mathrm{~m}^{-3}$. Under the same criteria as described in Sect. 4 the mean sf varies from 0.03 to 0.36 given $\rho_{\mathrm{i}}$ values ranging from 915 to $935 \mathrm{~kg} \mathrm{~m}^{-3}$ respectively. We used $925 \mathrm{~kg} \mathrm{~m}^{-3}$ for $\rho_{\mathrm{i}}$ as it represents the middle range of expected $\rho_{\mathrm{i}}$ in the study area. With this value an estimate of sf is provided, but we reiterate the dependence of the calculation on $\rho_{\mathrm{i}} .915 \mathrm{~kg} \mathrm{~m}^{-3}$ is considered a lower estimate of $\rho_{\mathrm{i}}$ as brine drainage is expected from the base of sea ice cores 
when undertaking the displacement technique. Assuming hydrostatic equilibrium we derive $927 \mathrm{~kg} \mathrm{~m}^{-3}$ for $\rho_{\mathrm{i}}$, a higher estimate in better agreement with the $934 \mathrm{~kg} \mathrm{~m}^{-3}$ reported by Gough et al. (2012). We suggest $934 \mathrm{~kg} \mathrm{~m}^{-3}$ as an upper bound to $\rho_{\mathrm{i}}$ (Timco and Frederking, 1996) in McMurdo Sound. Furthermore, under a simple measurement setup surface elevation could be slightly suppressed due to the loading of personnel and equipment near the drill-hole site. We found after testing this, that the sea ice surface may be suppressed by up to $0.01 \mathrm{~m}$ when such loading is present in close proximity to the drill-holes resulting in $\rho_{\mathrm{i}}$ overestimates of approximately $5 \mathrm{~kg} \mathrm{~m}^{-3}$. We also suggest that a large number of measurements using our method are necessary as sea ice is not necessarily in hydrostatic equilibrium over very short spatial scales. We do not expect this to have significantly influenced the mean of our freeboard values, and subsequently our $\rho_{\mathrm{i}}$ estimate, as most of our drill-holes were drilled at least $15 \mathrm{~m}$ away from such loading, and our estimate is based on an average of 35 separate drill-hole measurements (5 measurements at each site, 7 in total).

Though we have confidence that other sources of error play a smaller role, their influence cannot be entirely ignored. A $0.1 \%$ uncertainty in water density $\left(\rho_{\mathrm{w}}\right)$ has been reported by Albrecht et al. (2006). This results in a $\pm 1 \mathrm{~kg} \mathrm{~m}^{-3}$ variation in reported mean $\rho_{\mathrm{i}}$. Any larger variations in $\rho_{\mathrm{w}}$ would result in a larger range in calculated $\rho_{\mathrm{i}}$.

The estimate of sf for the sub-ice platelet layer has permitted the influence of the sub-ice platelet layer to be removed from sea ice thickness values derived from GNSS measurements of surface elevation. Without accounting for the sub-ice platelet layer, the mean deviation of estimated level ice thickness from drill-hole measured sea ice thickness is $0.39 \mathrm{~m}$. Taking account of the sub-ice platelet layer the mean deviation is reduced to $0.11 \mathrm{~m}$. Therefore, in areas of sea ice in close proximity to ice shelves it can be expected that thicknesses derived from freeboard or surface elevation may deviate from actual thickness by $12 \%$, with maximum deviations of the order of $19 \%$ as a direct result of not accounting for a sub-ice platelet layer. In our study results may be improved along certain GNSS profiles with better snow depth information.

Platelet ice and sub-ice platelet layers have been documented in many coastal Antarctic regions (Gough, 2012) making this link a key component of the Antarctic coastal sea ice regime. As the GNSS surface elevation sea ice thickness estimation operates under the same fundamental principles as satellite altimetry, this establishes an uncertainty in estimating sea ice thickness from satellite altimetry in proximity to ice shelves from the presence of a sub-ice platelet layer. Given that our estimate of sf is low in the range of reported values, the influence of the sub-ice platelet layer on sea ice thickness estimation from SE measurements could be even more significant. The variability of sf, both vertically through the sub-ice platelet layer and horizontally in a larger spatial sense could not be quantified. This will also play a role in the error of the estimation of sea ice thickness.

\section{Conclusions}

We have used an extensive drill-hole measurement campaign to estimate a solid fraction value of 0.16 for the subice platelet layer found under land-fast sea ice in McMurdo Sound. Using this information we were able to quantify the error associated with using satellite surface elevation measurements to estimate sea ice thickness. Sea ice thickness was overestimated on average by $12 \%$ in southern McMurdo Sound as a result of the buoyant influence of the sub-ice platelet layer on the sea ice cover above. The influence of the ice shelf is expected to extend beyond $200 \mathrm{~km}$ from the edge of the McMurdo Ice Shelf (Stevens et al., 2009). Platelet ice observations partly confirm this and have been recorded in sea ice cores $80 \mathrm{~km}$ north of the ice shelf edge (Dempsey et al., 2010). During fieldwork in 2013 the authors also measured a sub-ice platelet layer of $0.20 \mathrm{~m}$ in thickness at approximately the same distance. Though ice shelf water may still be influential on sea ice thickness out to and beyond $200 \mathrm{~km}$, the sub-ice platelet layers thickness clearly diminishes at such distances from the ice shelf margin. It is unlikely it still has a buoyant influence on the sea ice cover beyond a distance of $100 \mathrm{~km}$. We conclude that its influence may need to be considered in sea ice thickness investigations using satellite altimetry within $100 \mathrm{~km}$ of ice shelves. It should be noted, however, that ice shelf thickness is likely influential on whether supercooled water and platelet crystals can reach the upper few metres of the ocean and interact with sea ice.

Sub-ice platelet layer formation results from the advection of supercooled ice shelf water from beneath the McMurdo and Ross Ice Shelf cavities providing an oceanic heat sink for sea ice formation. This heat sink contributes to sea ice thicknesses exceeding $2.5 \mathrm{~m}$, at least double that of sea ice in pack ice areas of the Antarctic. Given the prevalence of ice shelves around the Antarctic and the fact that approximately $35 \%$ of the Antarctic coastline is fringed by fast ice in austral spring (Fraser et al., 2012), such interaction could be a primary driver of the sea ice thickness distribution near ice shelves. With adequate information on snow loading and using these anomalies in recorded sea ice thicknesses it may be possible to map ice shelf water presence in coastal Antarctica using satellite altimetry measurements.

Acknowledgements. The authors would like to acknowledge the K063 2011 fieldwork team including J. Beckers, A. Gough and K. Hughes and further the Scott Base staff of 2011. We would like to thank J.-F. Baure of Icam School of Engineering, Toulouse, France for processing GNSS data during a University of Canterbury supported internship. We are grateful for the logistics support of Antarctica New Zealand. Envisat ASAR data were received through 
CryoSat cal/val project 4512 . This work was carried out at Gateway Antarctica, University of Canterbury, Christchurch, New Zealand.

Edited by: J. Stroeve

\section{References}

Albrecht, N., Vennell, R., Williams, M., Stevens, C., Langhorne, P., Leonard, G., and Haskell, T.: Observation of sub-inertial internal tides in McMurdo Sound, Antarctica, Geophys. Res. Lett., 33, L24606, doi:10.1029/2006GL027377, 2006.

Bindschadler, R., Choi, H., Wichlacz, A., Bingham, R., Bohlander, J., Brunt, K., Corr, H., Drews, R., Fricker, H., Hall, M., Hindmarsh, R., Kohler, J., Padman, L., Rack, W., Rotschky, G., Urbini, S., Vornberger, P., and Young, N.: Getting around Antarctica: new high-resolution mappings of the grounded and freely-floating boundaries of the Antarctic ice sheet created for the International Polar Year, The Cryosphere, 5, 569-588, doi:10.5194/tc-5-569-2011, 2011.

Bintanja, R., Van Oldenborgh, G. J., Drijfhout, S. S., Wouters, B., and Katsman, C. A.: Important role for ocean warming and increased ice-shelf melt in Antarctic sea-ice expansion, Nature Geoscience, 6, 376-379, doi:10.1038/ngeo1767, 2013.

Comiso, J. C., Kwok, R., Martin, S., and Gordon, A. L.: Variability and trends in sea ice extent and ice production in the Ross Sea, J. Geophys. Res., 116, C04021, doi:10.1029/2010JC006391, 2011.

Dempsey, D. E., Langhorne, P. J., Robinson, N. J., Williams, M. J. M., Haskell, T. G., and Frew, R. D.: Observation and modeling of platelet ice fabric in McMurdo Sound, Antarctica, J. Geophys. Res., 115, C01007, doi:10.1029/2008JC005264, 2010.

Drosg, M.: Dealing with uncertainties: A guide to error analysis, Dordrecht, Netherlands, Springer, 2009.

Fraser, A. D., Massom, R. A., Michael, K. J., Galton-Fenzi, B. K., and Lieser, J. L.: East Antarctic landfast sea ice distribution and variability, 2000-08, J. Climate, 25, 1137-1156, doi:10.1175/JCLI-D-10-05032.1, 2012.

Gough, A. J.: Sea ice near and ice shelf, Doctor of Philosophy Thesis, University of Otago, Dunedin, New Zealand, 2012.

Gough, A. J., Mahoney, A. R., Langhorne, P. J., Williams, M. J. M., Robinson, N. J., and Haskell, T. G.: Signatures of supercooling: McMurdo Sound platelet ice, J. Glaciol., 58, 38-50, doi:10.3189/2012JoG10J218, 2012.

Gow, A. J., Ackley, S. F., Govoni, J. W., and Weeks, W. F.: Physical and Structural Properties of Land-Fast Sea Ice in McMurdo Sound, Antarctica, in Antarctic Sea Ice: Physical Processes, Interactions and Variability, edited by: Jeffries, M. O., American Geophysical Union, Washington, D.C., doi:10.1029/AR074p0355, 1998.

Haas, C. and Druckenmiller, M.: Ice thickness and roughness measurements, in: Sea-ice handbook, edited by: Eicken, H., University of Alaska Press, 2009.

Hellmer, H. H.: Impact of Antarctic ice shelf basal melting on sea ice and deep ocean properties, Geophys. Res. Lett., 31, 110307, doi:10.1029/2004GL019506, 2004.

Hughes, K. G., Langhorne, P. J., Leonard, G. H., and Stevens, C. L.: Extension of an ice shelf water plume model beneath sea ice with application in McMurdo Sound, Antarctica. J. Geophys. Res.Oceans, submitted, 2014.
Kurtz, N. T. and Markus, T.: Satellite observations of Antarctic sea ice thickness and volume, J. Geophys. Res., 117, C08025, doi:10.1029/2012JC008141, 2012.

Langhorne, P. J., Purdie, C. R., Smith, I. J., Leonard, G. H., Kempema, E. W., Petrich, C., Gribble, M. A., Bond, P. E., and Haskell, T. G.: Antarctic landfast sea ice: the role of platelet ice, edited by: Saeki, H. (Ed.), in: IAHR International Symposium on Ice. Sapporo, Japan: Nakanishi Publishing Co. Ltd., 2006.

Mahoney, A. R., Gough, A. J., Langhorne, P. J., Robinson, N. J., Stevens, C. L., Williams, M. J. M., and Haskell, T. G.: The seasonal appearance of ice shelf water in coastal Antarctica and its effect on sea ice growth, J. Geophys. Res., 116, C11032, doi:10.1029/2011JC007060, 2011.

Parkinson, C. L. and Cavalieri, D. J.: Antarctic sea ice variability and trends, 1979-2010, The Cryosphere, 6, 871-880, doi:10.5194/tc-6-871-2012, 2012.

Price, D., Rack, W., Haas, C., Langhorne, P. J., and Marsh, O.: Sea ice freeboard in McMurdo Sound, Antarctica, derived by surfacevalidated icesat laser altimeter data, J. Geophys. Res.-Oceans., 118, 3636-3650, doi:10.1002/jgrc.20266, 2013.

Purdie, C. R., Langhorne, P. J., Leonard, G. H., and Haskell, T. G.: Growth of first-year landfast Antarctic sea ice determined from winter temperature measurements, Ann. Glaciol., 44, 170-176, doi:10.3189/172756406781811853, 2006.

Rack, W., Haas, C., and Langhorne, P. J.: Airborne thickness and freeboard measurements over the McMurdo Ice Shelf, Antarctica, and implications for ice density, J. Geophys. Res.-Oceans., 118, 5899-5907, doi:10.1002/2013JC009084, 2013.

Robinson, N. J., Williams, M. J. M., Stevens, C. L., Langhorne, P. J., and Haskell, T. G.: Evolution of a supercooled Ice Shelf Water plume with an actively growing subice platelet matrix, J. Geophys. Res. Oceans, 119, doi:10.1002/2013JC009399, 2014.

Spreen, G., Kern, S., Stammer, D., Forsberg, R., and Haarpaintner, J.: Satellite-based estimates of sea-ice volume flux through fram strait, Ann. Glaciol., 44, 321-328, doi:10.3189/172756406781811385, 2006.

Stevens, C. L., Robinson, N. J., Williams, M. J. M., and Haskell, T. G.: Observations of turbulence beneath sea ice in southern McMurdo Sound, Antarctica, Ocean Sci., 5, 435-445, doi:10.5194/os-5-435-2009, 2009.

Timco, G. W. and Frederking, R. M. W.: A review of sea ice density, Cold Reg. Sci. Technol., 24, 1-6, 1996.

Trodahl, H. J., McGuinness, M. J., Langhorne, P. J., Collins, K., Pantoja, A. E., Smith, I. J., and Haskell, T. G.: Heat transport in McMurdo Sound first-year fast ice, J. Geophys. Res.-Oceans., 105, 11347-11358, doi:10.1029/1999JC000003, 2000.

Uto, S., Shimoda, H., and Ushio, S.: Characteristics of sea-ice thickness and snow-depth distributions of the summer landfast ice in Lützow-holm Bay, East Antarctica, Ann. Glaciol., 44, 281-287, doi:10.3189/172756406781811240, 2006.

Worby, A. P., Geiger, C. A., Paget, M. J., Van Woert, M. L., Ackley, S. F., and Deliberty, T. L.: Thickness distribution of Antarctic sea ice, J. Geophys. Res., 113, C05S92, doi:10.1029/2007JC004254, 2008.

Zwally, H. J., Yi, D., Kwok, R., and Zhao, Y.: ICESat measurements of sea ice freeboard and estimates of sea ice thickness in the Weddell Sea, J. Geophys. Res., 113, C02S15, doi:10.1029/2007JC004284, 2008. 